\title{
Influence of Low Temperature Plasma Treatment on the surface, Optical and DC Electrical Properties of jute
}

\author{
Md. Masroor Anwer ${ }^{1}$, A. H. Bhuiyan ${ }^{2}$ \\ ${ }^{I}$ Textile Physics Division, Bangladesh Jute Research Institute (BJRI), Dhaka-1207, Bangladesh, \\ ${ }^{2}$ Department of Physics, Bangladesh University of Engineering and Technology (BUET), Dhaka-1000, \\ Bangladesh.
}

\begin{abstract}
Low temperature plasma (LTP) treatment, a kind of environmentally friendly surface modification technique, was applied to ligno-cellulosic jute fibre with the use of nonpolymerizing gas, namely argon, at various discharge power levels and exposure times with a definite flow rate. The surface morphology, optical and direct current $(D C)$ electrical properties of both raw and plasma treated jute were studied. By means of scanning electron microscopy (SEM), the influence of treatment time and discharge power on the surface morphology of the surface of jute fibres were studied and were compared with that of raw jute. SEM microphotographs reveal that the roughness of the fibre surfaces increases with the increase of discharge power and exposure time. This is caused due to the bombardment of high energetic ions on the fibre surface and the fibres become sputtered. Ultraviolet visible (UV-Vis.) spectroscopic analysis reveals that the band gap of jute increases with the increase of discharge power as well as exposure time. The change in the DC electrical resistivity of the LTP-treated jute fibre was in good agreement with the above findings.
\end{abstract}

Key words: Band gap, Jute fibre, Moisture, Morphology, Plasma treatment.

\section{Introduction}

In recent years, environmental concerns such as global warming, energy consumption and the desire to obtain products from renewable sources has skyrocketed the consumption of natural fibres for total or partial substitution of petroleum-based synthetic fibres which are neither biodegradable nor renewable [1]. Plant fibres such as jute, hemp, flax, coconut fibre etc. have some interesting characteristics, e.g., cost effectiveness, renewable, available in huge quantities, low fossil-fuel energy and low cost compared to synthetic fibres such as glass, carbon etc.[2]. Thus, natural fibres have attracted attention for their applications in science and engineering, where lightweight is required. However, all plant fibres are hydrophilic and their moisture contents can reach up to $3 \%-13 \%$ [3], which limits their life span. The applications of natural fibres as reinforcements in composite materials require a strong adhesion between fibre and the synthetic matrix. But the hydrophilic nature of natural fibre causes weakening in the adhesion. Physical and chemical treatments can be used to optimize this interface [4]. The literature abounds with references to the surface modification of fibres by chemical, physical and physiochemical means [5-9]. In the past few years interest has increased in the use of low temperature plasma (LTP) technique which is a promising approach for surface modifications of human made as well as natural fibres $[10,11]$. As a type of environmentally friendly physical surface modification technique, LTP treatment is one of the methods used to modify surfaces in a dry process [12,13]. Advantages of this technique, compared to a conventional wet process, are: (i) because of the very thin treatment layer, only the surface is modified without interfering the bulk properties and (ii) the process is simpler-fewer steps and less time are required, involving no chemicals. Plasma treatment is distinguished from plasma polymerization by the nature of the gases used. For example, most organic compounds, even methane, can polymerize in a plasma state to form thin layer, a process referred to as plasma polymerization. In this case, the top of the substrate is covered by plasma polymer. On the other hand, inert gases, such as, Argon (Ar), Neon ( $\mathrm{Ne})$ and Helium $(\mathrm{He})$ never form polymers in a plasma state [14]. However, these plasmas can cause some chemical and physical reactions on the surface of substrates because of highly energetic species such as free radicals, ions, photons and ultraviolet (UV) radiations. The high-energy electrons and low-energy molecular species in a LTP can initiate reactions in the plasma volume without excessive heat causing substrate degradation [15]. LTP are particularly suited to apply to textile processing because most textile materials are heat sensitive polymers. In addition, it is a versatile technique, where a large variety of chemically active functional groups can be incorporated into the textile surface. Plasma treatment is controlled by applied power for gas discharge, nature of the gas, position of the fibres inside plasma and exposure time. As is well known, plasma treatments has two sorts of effect on fibre surfaces; one is physical sputtering, using an inert gas such as argon to modify the surface, the other is chemical graft, inducing some polar radicals, such as oxygen and nitrogen etc., to functionalize the surface of the fibres. A lot of literatures have been published on the plasma treatment of natural fibres for improving surface, 
mechanical, physical and thermal properties as well as composites where jute was used as a reinforcing material. However, research work so far has done on comparative study concerning the impact of plasma treatment upon the changes of band gap as well as electrical resistivity of the jute fibre is sparse. In the present work, jute fibres were treated with low temperature Ar plasma for different discharge power and exposure time. The ultimate goal of the research work is designed to inspecting raw jute, LTP treated jute surfaces by scanning electron microscopy (SEM) at very high magnifications, optical band gaps of raw, and LTP treated jute fibre by UV-Vis. spectroscopy and DC electrical resistivity by a high impedance electrometer.

\subsection{Low temperature plasma treatment}

\section{Experimental Details}

Jute fibres were collected from the local market in Bangladesh. The jute fibres were introduced into a bell jar type capacitively coupled glow discharge reactor, which was made up of a cylindrical Pyrex glass belljar having $0.15 \mathrm{~m}$ in inner diameter and $0.18 \mathrm{~m}$ in length. It consists of a pair of circular stainless steel electrodes with their planes parallel to each other. They are positioned cylindrically symmetric and capable of axial movement. The electrodes were connected to high-tension AC power supply $(3.5 \mathrm{kV}, 2.8 \mathrm{~kW})$. To sustain a glow discharge i.e. for getting proper and uniform plasma, the conductive electrodes are separated $0.035 \mathrm{~m}$ apart from each other. In order to exposed all through uniform LTP treatment on the samples surface, the fibres (length of each fibre: $0.08 \mathrm{~m}$ ) were inserted between the two metallic electrodes by a carrier. After placing the jute fibres between pair of electrodes, the glow discharge chamber was evacuated by a rotary pump (Vacuubrand, Vacuubrand GMBH and Co, Germany) at a pressure of $1.33 \mathrm{~Pa}$. Argon was considered as a plasma gas for treating the jute fibre. The discharge powers were adjusted at 50,75 and $100 \mathrm{~W}$ at a line frequency of $50 \mathrm{~Hz}$ with the duration of exposure times were 5, 10, 15 and $20 \mathrm{~min}$. of LTP treatment of the surface of jute fibres. In all treatments, Ar gas was introduced into the reaction chamber by a flowmeter (Model: 1355K4BQ8F6CG, Emerson electric, Pennsylvania, USA) at a flow rate of $0.2 \mathrm{~L} / \mathrm{min}$. which was maintained by a needle valve. Fig. 1 shows a flow-chart of a plasma treatment system which was used in this experiment.

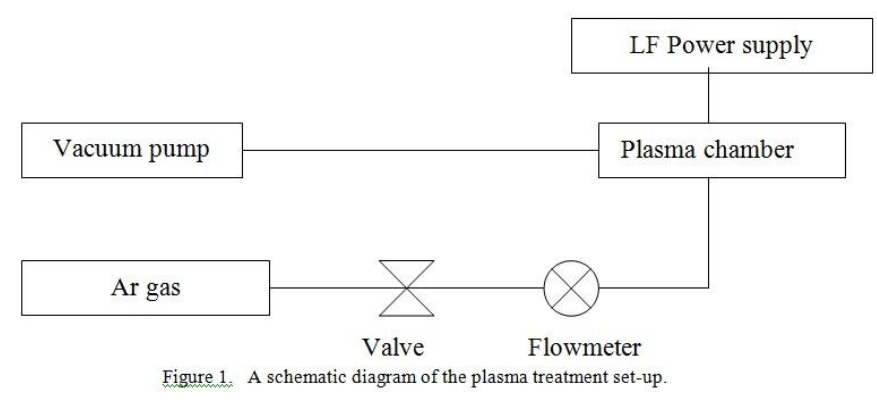

After plasma treatment has been finished, and the vacuum chamber was vented, jute samples were then removed and handled carefully in order to avoid possible surface contamination to the fibres. Later, the plasma treated fibres were immediately placed into a desiccator with the silica gel.

\subsection{Characterization Techniques}

\subsubsection{SEM analysis}

The surface morphology of the raw and LTP treated jute fibres were examined with a SEM (Model: S50, FEI Qunta Inspect, The Netherlands) operated at $25 \mathrm{kV}$ in low vacuum control at $50 \mathrm{~Pa}$. The surfaces of the jute fibres were examined at $2000 \times$ magnification.

\subsubsection{Uv-Vis. analysis}

The UV-Vis spectra of raw and plasma-treated jute fibres at various exposure time with different discharge power were recorded at room temperature in absorption mode using a Shimadzu UV-160A spectrophotometer (Shimadzu, Tokyo, Japan), in the wavelength range of 200 to $1100 \mathrm{~nm}$. The absorption spectra were recorded both for raw and plasma treated jute at various exposure time with different discharge power.

\subsubsection{Electrical characteristics}

The current density-voltage (J-V) characteristics of tablet formed jute fibres were studied at room temperature in the DC voltage range of 5- $100 \mathrm{~V}$. The current pass through the tablet was measured by a high impedance Keithley 614 electrometer (Keithley Instruments, Inc.,USA) and the DC voltage was applied by an Agilent 6545A stabilized DC power supply (Agilent Technologies Japan Ltd, Tokyo, Japan). The voltage was increased step by step. The samples were depolarized before each measurement run. 
Influence of Low Temperature Plasma Treatment on the surface, Optical and DC Electrical

\subsection{Sample preparation for the Uv-Vis. and DC electrical measurements}

In preparing the samples, both raw and plasma treated jute fibres were cut into small pieces of sizes of about 1.0-2.0 mm. By mortar and pestle these small pieces of jute fibres were ground, crushed and mixed in order to convert into powder form. Finally, the jute powders were seived by a very fine and thin net to make the powder finer. The powdered form jute of about $200 \mathrm{mg}$. was then put in a specially prepared high-pressure die. In order to make the tablets from jute powder, a high pressure (14000 psi) was applied by a hydraulic press (Model: X30659, 0-16000 psi, Mold Pressure, P.S.I: 1" and 5/4" Mold, Will Corporation, NY, USA). The diameter and the thickness of each equipped tablet was 13.5 and $1.5 \mathrm{~mm}$ respectively. In these way thirteen types tablets (one tablet was for raw jute and another twelve were for LTP treated jute) were prepared with treated jute samples of different discharge power and exposure time. For DC parameters measurements suitable electrical contacts were made by coating opposite faces with silver paste. Thereby forming parallel plate capacitor geometry. All the tablets were oven-dried at $100^{\circ} \mathrm{C}$ before characterization of the samples.

\section{Results And Discussion}

\subsection{Surface morphology}

SEM microphotographs of raw jute fibre and LTP treated jute fibres by Ar gas at various discharge powers $(50,75$ and $100 \mathrm{~W})$ and exposure times $(5,10,15$ and $20 \mathrm{~min}$.) were taken in this experimental work. Only raw jute and 10, 20 min. LTP treated jute with 50 and $100 \mathrm{~W}$ discharge powers are presented here in Fig. 2(a)-(e).
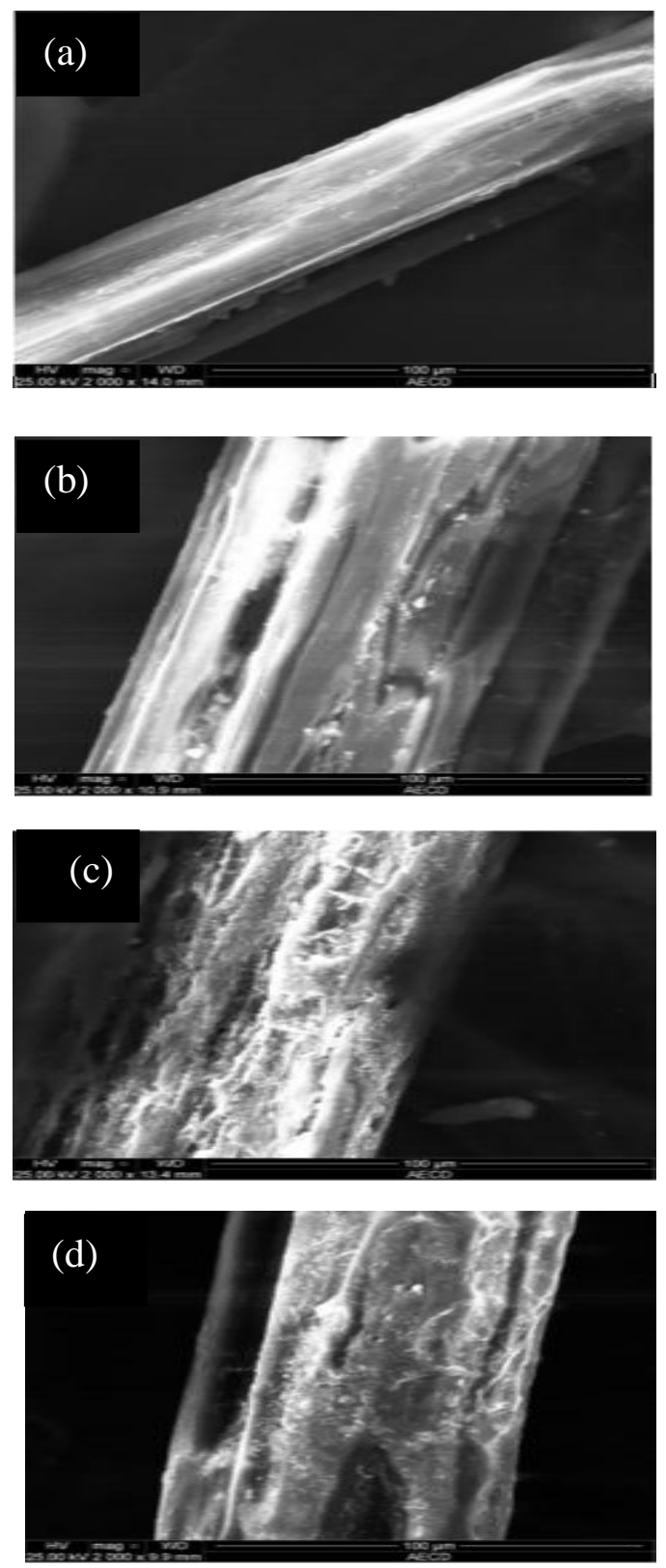

www.iosrjournals.org 




Figure 2: SEM microphotographs of different jute fibres (a) raw jute (b) $50 \mathrm{~W}, 10 \mathrm{~min}$. (c) $50 \mathrm{~W}, 20 \mathrm{~min}$. (d) $100 \mathrm{~W}, 10 \mathrm{~min}$. and (e) $100 \mathrm{~W}, 20 \mathrm{~min}$. LTP treated jute fibre by Ar gas.

It can be visually verified that the surface of raw jute at Fig. 2(a) is smooth and shows no roughness. Fig. 2(b)-(e) illustrate the action of plasma treatment with Ar on the fibre surface for different exposure time and discharge power. Fig. 2(b)-(c) associated with 50 and $100 \mathrm{~W}$ discharge powers of 10 min. treatment time presents a surface like rough and fragmented. Fig. 2(d)-(e), associated with 50 and $100 \mathrm{~W}$ discharge powers of $20 \mathrm{~min}$. treatment time shows more roughness and also shows degradation on fibre surface. Besides, Fig. 2(e) shows the formation of pits on the fibre surface, likely by the physical sputtering mechanism of plasma causing more degradation on the fibre surface [16]. According to the physical sputtering mechanism the longer the duration of physical sputtering of LTP treatment, the more severe the modification of the fibre surface which are shown by SEM microphotographs (figure 2). In addition, the higher the discharge power applied the more kinetic energy the plasma species will carry. Hence, there will be a change in the total amount of the excited particles inside the plasma and their energy level accordingly when the input power increases under a constant pressure. As a result strong intensity of plasma action happened on the fibre surfaces due to the increase of charged ion concentration. $[17,18]$. It is noted that jute fibre contains organic molecules. Gaseous plasma may also introduce degradation and chain scission in fibre [19]. Plasma gas may also react with some polymer constituents inside the fibre and ultimately causes rupture and increases the surface roughness, voids and spaces in the jute fibre. Thus, plasma treatments result in significant change of morphology of the fibre surface.

\subsection{Ultraviolet-Visible spectroscopic analysis}

Fig. 3 shows the representative graphs of absorbance vs. wavelength curves of raw jute and LTP treated jute with different exposure time at $100 \mathrm{~W}$ discharge power.

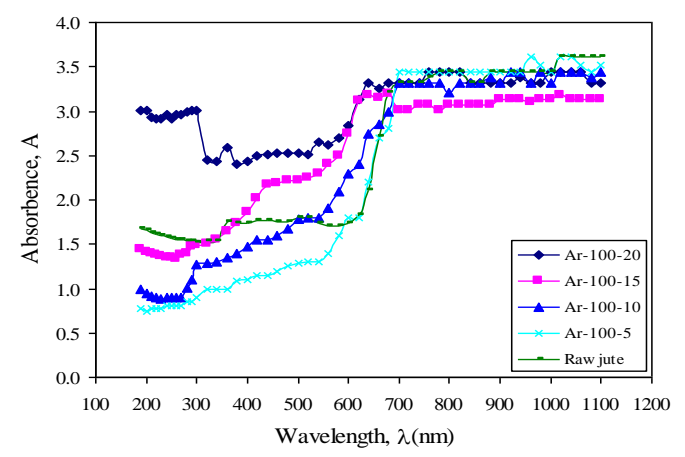

Figure 3 Absorbance vs. wavelength curves for Ar plasma at $100 \mathrm{~W}$

From the above Fig., it is seen that at high wavelengths $(700-1100 \mathrm{~nm})$ the absorption is high and almost constant. But from 700 to $600 \mathrm{~nm}$ the absorption level falls sharply. Again, from 600-200 nm the absorption falls gradually with the decrease of wavelength. The absorption coefficient, $\alpha$, was calculated from the absorbance data of figure 3 using the relation [20]

$$
\alpha=2.303(\mathrm{~A} / \mathrm{d})
$$

where, $\mathrm{A}$ is the absorbance and $\mathrm{d}$ is the thickness of the jute tablet. The spectral dependence of $\alpha$ as a function of photon energy, hv, is shown in Fig. 4. The dependence of $\alpha$ on hv helps to study the band structure and to measure the band gap. 


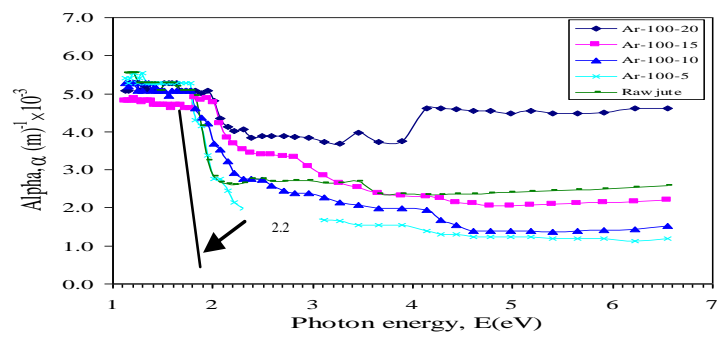

Figure 4 Absorption Coefficient Vs. Photon energy curves for Ar plasma at $100 \mathrm{~W}$ (An example of determining of band gap is shown in the case of raw jute fibre)

From the Fig. 4 the optical band gap, $\mathrm{E}_{\mathrm{g}}$, are determined from the intercept of the linear part of the curves extrapolated to zero $\alpha$ in the energy axis. In this way, the values of $E_{g}$ are obtained for the raw jute and all LTP treated jute, are plotted versus exposure time, and discharge power in Fig. 5 and Fig. 6 respectively.

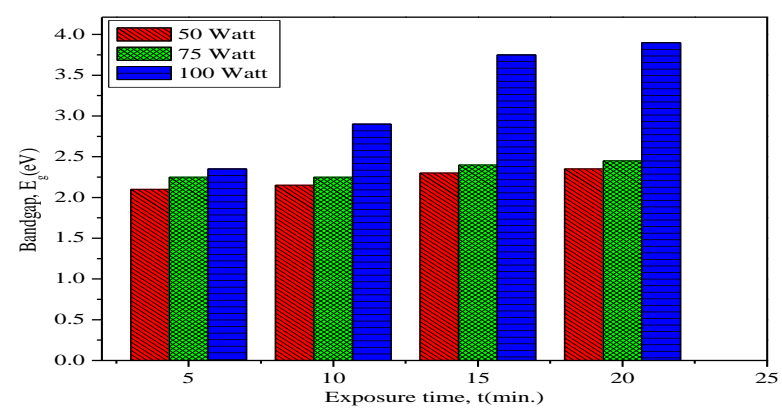

Figure 5 Optical band gap vs. exposure time at different power of Ar gas



Figure 6 Optical band gap vs. discharge power at different time of Ar gas

It is seen from the Fig. 5 and Fig. 6 that $\mathrm{E}_{\mathrm{g}}$ of jute fibres increases with the increase of both exposure time as well as discharge power. The reasons behind the increase of $E_{g}$ with the increase of exposure time and discharge power may be explained as follows: Chemically jute fibre possesses high content of semicrystalline and amorphous materials, such as hemi-cellulose and lignin. Also, due to the presence of the hydroxyl groups on the fibre surface and in the amorphous region, the jute fibres can absorb moisture from the atmosphere under standard conditions of temperature and pressure [6]. So, the jute fibres are hygroscopic and hydrophilic in nature. When jute fibre is exposed to LTP, energetic charged particles inside the plasma are able to interact chemically with the surface to be treated. Such interactions can also affect the material properties and the moisture content of the treated fibre decreases due to the surface modification of the fibres. In the LTP process, the water $\left(\mathrm{H}_{2} \mathrm{O}\right)$ dissociates into $\mathrm{H}$ and $-\mathrm{OH}$ species by energetic gaseous ion bombardment. The temperature sensitive jute fibres were dried more effectively in plasma without damaging its constituents and also improved the crystallinity of the fibres [21]. So, band gaps increases with increase of exposure times and discharge powers.

\subsection{Electrical characteristics}

The representative current density- voltage (J-V) graphs of tablet formed raw jute and LTP treated jute with different exposure times at $100 \mathrm{~W}$ discharge power are presented in Fig. 7. 


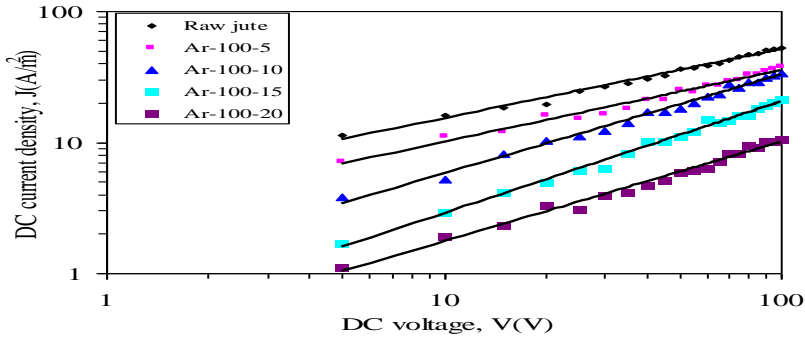

Figure $7 \mathrm{~J}-\mathrm{V}$ plots for raw and treated jute for Ar plasma at different time at $100 \mathrm{~W}$ The representative current density- voltage (J-V) graphs of tablet formed raw jute and LTP treated jute with different discharge power at 10 min. exposure time are presented in Fig. 8.

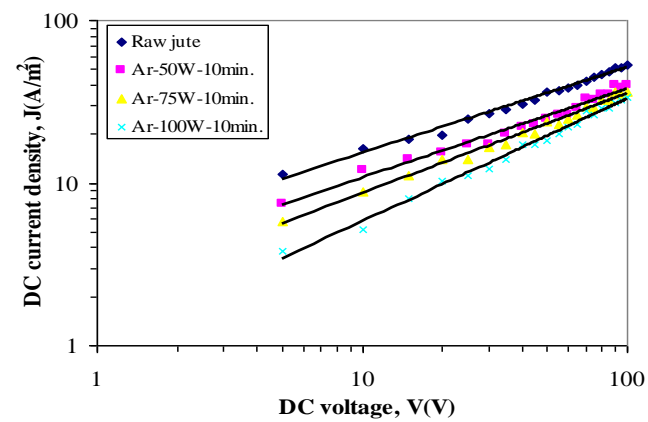

Figure $8 \mathrm{~J}-\mathrm{V}$ plots for raw and treated jute for Ar plasma with different power at $10 \mathrm{~min}$.

It is seen from above curves that they follow a power law of the form $\mathrm{J} \alpha \mathrm{V}^{\mathrm{n}}$, where $\mathrm{n}$ is a power index. It is also observed from above curves that with the increase of exposure time and discharge power, the current flow through the tablet decreases.

The electrical resistivities of LTP treated jute by Ar plasma at different exposure time and discharge power are shown in Fig. 9 and Fig. 10.

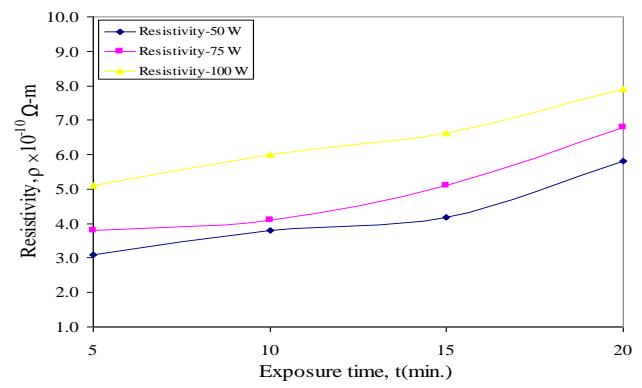

Figure 9 Resitivity vs. exposure time for Ar plasma at different discharge power.

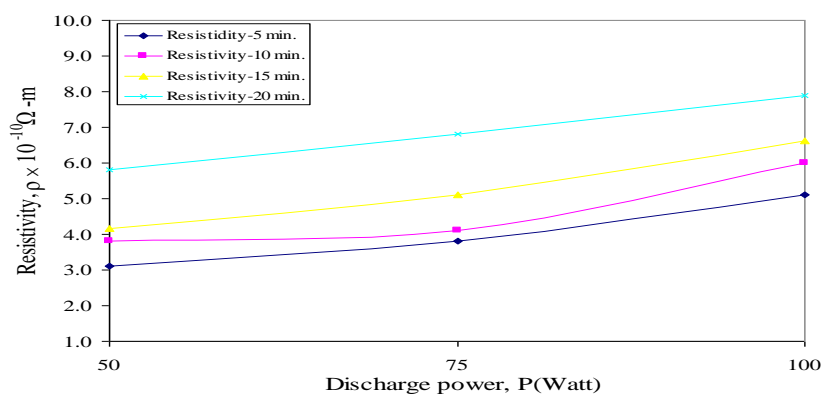

Figure 10 Resitivity vs. discharge power for Ar plasma at different exposure time.

It is observed from Fig. 9 and Fig. 10 that resistivity increases with exposure time as well as discharge power. This is in good agreement with the results found by the UV-Vis. analysis where the band gap increases due to LTP treatment as discussed in the previous section. 


\section{Conclusions}

Once the plasma power was applied, surface morphological changes of jute observed on the fibre surface were obviously evident according to the treatment time and discharge power. Because of the physical sputtering and chemical etching effect, surface roughness of the fibres increases with increase of exposure times and discharge powers. The optical band gap of jute increases with the increase of plasma treatment time as well as discharge power. This happens because of the LTP process is a candidate process for moisture removal. Because of this, jute fibres become dry and hydrophobic. So, the electrical resistivity increases with the increase of discharge power and treatment time. These results are verified and are good agreement with the results obtained from DC electrical measurements. Although the surface property alterations obtained with plasma treatment are very complex, the treatment is environmental friendly, it optimizes the surface properties of materials without altering their bulk characteristics. Also, the consumption of chemicals is very low due to the physical process. The most important factor is that the substrate surface properties change significantly after a short plasma treatment. This alone has significant implications for the jute industry.

\section{Acknowledgements}

One of the authors (M. M. Anwer) is thankful to the authorities of Bangladesh Agricultural Research Council, Dhaka-1215, Bangladesh, for granting a Ph.D. fellowship in his favor and Bangladesh Jute Research Institute, Dhaka-1207, Bangladesh, for sanctioning three and half years deputation for Ph.D. research.

\section{References}

[1] E. Sinha, S K. Rout and P K. Barhai, Study of the structural and thermal properties of plasma treated jute fibre, Journal of Applied Physics A, 192(2), 2008, 283-290.

[2] S. Mishra, A.K. Mohanty, L.T. Drzal, M. Misra, S. Parija, S.K. Nayak and S.S. Tripathy Studies on mechanical performance of biofibre/glass reinforced polyester hybrid composites, Composite Science and Technology, 63(10), 2003, $1377-1385$.

[3] A. K. Bledzki, S. Reihmane, and J. Gassan, Properties and modification methods for vegetable fibers for natural fiber composites, Journal of Applied Polymer Science, 59(8), 1960, 1329-1336.

[4] A.K. Bledzki, and J. Gassan, Composites reinforced with cellulose based fibres, Journal of Progress in Polymer Science, 24(8), 1999, 221-274.

[5] L. Y.Mwaikambo, and M. P. Ansell, $2^{\text {nd }}$ International Wood and Natural Fiber Composites Symposium, 1999, Kassel/Germany.

[6] U. U. Modibbo, B. A Aliyu, I. I. Nkafamiya, and A.J. Manji, The effect of moisture imbibition on cellulosic bast fibres as industrial raw materials, International Journal of Physical Sciences, 2(7), 2007, 163-168.

[7] F. Corrales, F. Vilaseca, M. Llop, J. Girones, J.A. Mendez and P. Mutje, Chemical modification of jute fibres for the production of green-composites, Journal of Hazardous Materials, 144 (3), 2007, 730-735.

[8] J. Gassan, and A. K. Bledzki, Alkali treatment of jute fibers: Relationship between structure and mechanical properties, Journal of Applied Polymer Science, 71(4), 1999, 623-629.

[9] A. Mukherjee,, P. K. Ganguly and D. Sur, Structural Mechanics of Jute: The Effects of Hemicellulose or Lignin Removal, Journal of Textile Institute, 84(3), 1993, 348-353.

[10] I. Luciu, B. Mitu, V. Satulu, A. Matei, and G. Dinescu, Low and atmospheric pressure plasma treatment of natural textile fibres, XXIII-rd Int. Symp. On Discharge and Electrical Insulation in Vacuum-Bucharest, 2008.

[11] Y. Seki, M. Sarikanat, K. Sever, S. Erden and A. Gulec, Effect of the low and radio frequency oxygen plasma treatment of jute fibre on mechanical properties of jute fibre/polyster composite, Fibres and polymers, 11(8), 2010, 1159-1164.

[12] Y. Qiu, C. Zhang, Y. J. Hwang, B. L. Bures and M. McCord, The effect of atmospheric pressure helium plasma treatment on the surface and mechanical properties of ultrahigh-modulus polyethlene fibres, Journal of adhesion science and Technology, 16(1),2002, 99-107.

[13] A. Demir, Y. Seki, E. Bozaci, M. Sarikanat, S. Erden, K. Sever and E. Ozdogan, Effect of the atmospheric plasma treatment parameters on jute fabric: The effect on mechanical properties of jute fabric/polyester composites, Journal of Applied Polymer Science, 121(2), 2011, 634-638.

[14] K. N. Pandiyaraj and V. Selvarajan, Non-thermal plasma treatment for hydrophilicity improvement of grey cotton fabrics, Journal of Materials Processing Technology, 199(1-3), 2008, 130-139.

[15] Y.U. Iriyama, T. Yasuda, D. L. Cho, and H. Yasuda, Plasma surface treatment on nylon fabrics by fluorocarbon compounds, Journal of Applied Polymer Science, 39(2), 1990, 249-264.

[16] H. Yasuda, Plasma Polymerization, Academic Press, New York, 1985.

[17] E. Sinha, Effect of cold plasma treatment on macromolecular structure, thermal and mechanical behavior of jute fibre, Journal of Industrial Textiles, 38(4), 2009, 317-338.

[18] E. Bozaci, K. Sever, A. Demir, Y. Seki, M. Sarikanat and E. Ozdogan, Effect of the atmospheric plasma treatment parameters on surface and mechanical properties of jute fabric, Fibres and Polymers, 10(6), 2009, 781-786.

[19] M. M. Morshed, M. M. Alam and Daniels, S. M., Plasma treatment of natural jute fibre by RIE 80 plus plasma tool, Plasma Science and Technology, 12(3), 2010, 325-329.

[20] S. K. J. Al-Ani, A. A. Higazy, Optical properties of Barium-Germinate glasses, Journal of Material Science, 26(2), 1991, 36703679 .

[21] M. M. Morshed, M. M. Alam and S.M. Daniels, Moisture removal from natural jute fibre by plasma drying process, Plasma chemistry and plasma processing journal, 32(2), 2011, 249-258. 